\title{
Analisis Clustering Pengelompokan Penjualan Paket Data Menggunakan Metode K-Means
}

\author{
Dimas Galang Ramadhan ${ }^{1}$, Indri Prihatini ${ }^{2}$, Febri Liantoni ${ }^{3}$ \\ 1,2,3 Pendidikan Teknik Informatika dan Komputer, Fakultas Keguruan dan Ilmu Pendidikan, \\ Universitas Sebelas Maret
}

Diterima 01 April 2021

Disetujui 13 Juni 2021

\begin{abstract}
At present, the COVID-19 pandemic requires all activities based in the network, starting from work, college, school, and everything based on the network. Certain provider users will experience excessive data plan usage. This also affects a counter that sells data packages, which must provide several data package services following current conditions. This research was conducted to analyze the grouping of sales of data packages that are often purchased by customers in a counter by using the K-Means method. The K-Means method is used because the K-Means algorithm is not influenced by the order of the objects used, this is proven when the writer tries to determine the initial cluster center randomly from one of the objects in the first calculation. sales of data packages at a counter. Variables used include Price, Active period, and several data packages. The K-Means Cluster Analysis algorithm is basically applied to the problem of understanding consumer needs, identifying the types of data package products that are often purchased. The K-Means algorithm can be used to describe the characteristics of each group by summarizing a large number of objects so that it is easier.
\end{abstract}

Index terms-K-Means, Clustering, Data Mining

\section{Pendahuluan}

Salah satu langkah dalam knowledge discovery databases adalah Data Mining. Data Mining merupakan teknik analisis data untuk mendapatkan informasi yang tersembunyi dari data yang kompleks dalam jumlah besar. Salah satu teknik analisa Data Mining adalah Cluster Analysis (Analisis Kelompok) atau dikenal sebagai Clustering. Clustering merupakan sebuah metode analisis dengan tujuan mengelompokkan data berdasarkan karakteristik objek pada suatu wilayah yang sama. Algoritma K-Means digunakan dalam mengembangkan metode Clustering, algoritma ini merupakan algoritma pengelompokan data secara nonhierarki (sekatan) yang membagi data kedalam dua atau lebih kelompok (cluster) dengan karakteristik sama.

Pada penelitian sebelumnya metode clustering digunakan untuk mengelompokkan daun berdasarkan fitur moment invarian. Pada penelitian ini metode clustering yang digunakan yaitu Hierarchical Clustering dan K-Means [1], [2].
Konter merupakan salah satu bidang usaha penjualan pulsa dan paket data. Dimana untuk situasi pandemi sekarang ini paket data banyak sekali dicari untuk kebutuhan aktivitas dalam jaringan, penggunaan provider dan jumlah paket data yang sering digunakan konsumen membuat bidang usaha ini harus menentukan jenis provider, jumlah paket data dan harganya yang akan diperbanyak stoknya berdasarkan penggunaan pelanggan. Oleh karena itu diperlukan data yang cukup agar bisa dianalisis lebih lanjut dan menghasilkan sebuah informasi yang tepat.

Berdasarkan hal tersebut diharapkan sebuah konter dapat menentukan suatu pengelompokan untuk menentukan provider, jumlah paket data, serta harga yang akan di perbanyak stoknya. Penulis juga mengupayakan agar bisa memberikan rangsangan kepada pengolah data supaya bisa mengumpulkan informasi lebih banyak yang dibutuhkan oleh sebuah konter, sehingga bisa menghasilkan pilihan yang tepat untuk menjawab kebutuhan dari sebuah Konter. Hasil penelitian ini akan memberikan informasi pilihan paket favorit yang diminati.

\section{Metode PenElitian}

\section{A. Clustering}

Clustering adalah metode yang digunakan untuk membagi rangkaian data menjadi beberapa group berdasarkan kesamaan-kesamaan yang telah ditentukan sebelumnya [2], [3]. Cluster adalah sekelompok atau sekumpulan objek-objek data yang similar satu sama lain dalam cluster yang sama dan disimilari terhadap objek-objek yang berbeda cluster [4][1].

Data dari clustering memiliki tujuan, yaitu untuk meminimalisasikan objektif function yang diatur dalam proses clustering, dimana pada umumnya berusaha meminimalisasikan variasi dalam suatu cluster dan antar cluster.

\section{B. Algoritma Klasterisasi K-Means}

Metode algoritma K-Means digunakan pada penelitian ini untuk menentukan kelompok (cluster) yang paling baik untuk pemilihan provider, jumlah paket data, serta harga yang akan diperbanyak di Konter Plus Ultra Pabelan. Sehingga peluang untuk menambah 
penghasilan penjualan semakin banyak dengan menambah stok provider yang paling banyak dibeli.

Metode K-Means merupakan metode pengelompokkan data berdasarkan titik pusat cluster (centroid) [5]. Metode K-Means bertujuan untuk mengelompokan data dengan karakteristik yang sama dalam satu cluster.

Langkah awal proses clusterisasi data dengan menggunakan metode K-Means adalah penentuan titik pusat awal cj, pada umumnya penentuan titik awal centroid didapatkan secara acak [5], [6]. Banyaknya centroid cj yang didapatkan sesuai dengan jumlah cluster yang ditentukan di awal. Setelah titik pusat awal terbentuk kemudian langkah selanjutnya menghitung jarak tiap data xi dengan titik pusat awal ke-j sampai k, dinotasikan dengan $\mathrm{d}(\mathrm{xi}, \mathrm{cj})$.

Kelanjutan dari jarak data dengan titik pusat tersebut dicari jarak terdekat sehingga data akan dikelompokkan berdasarkan centroid terdekat [7]. Langkah selanjutnya yaitu memperbarui titik centroid dengan cara menghitung rata-rata jarak dari seluruh data dengan centroid. Kemduian kembali lagi ke langkah awal. Iterasi ini dilakukan berulang-ulang hingga mendapatkan titik centroid sudah tidak berubah (konstan)

Metode K-Means digunakan tergantung dari data yang ada dan konklusi yang ingin dicapai dengan aturan sebagai berikut : (a) Jumlah Cluster perlu diinputkan. (b) Hanya memiliki atribut numeric [8].
Metode K-Means awalnya mengambil beberapa komponen dari populasi sebagai pusat titik awal atau pusat cluster awal [9]. Pada tahapan ini pusat cluster ditentukan secara acak serta menandai komponen tersebut ke dalam salah satu pusat cluster yang telah didefinisikan, berdasarkan hasil dari jarak minimum data dengan titik pusat cluster. Titik pusat awal (cluster) selanjutnya dihitung kembali hingga semua komponen data dikelompokkan kedalam masingmasing pusat cluster sehingga terbentuk posisi pusat cluster yang baru.

Terdapat 2 proses pada algoritna K-Means yaitu proses pencarian anggota dari tiap-tiap cluster dan proses pendeteksian lokasi pusat tiap cluster. Cara kerja algoritma K-Means (a) Menentukan k sebagai jumlah cluster yang ingin dibentuk. (b) Bagkitkan k titik pusat cluster awal secara acak. (c) Hitung jarak masing -masing data terhadap titik pusat cluster. (d) Pilih setiap data dengan titik pusat cluster terdekat. (e) Tentkan titik pusat cluster baru dengan meghitung rata-rata data yang terletak pada titik awal cluster yang sama. (f) Kembali pada langkah ke-3 jika posisi titik awal cluster lama dengan yang baru masih berbeda.

\section{HASIL DAN PEMBAHASAN}

Pada penelitian ini, terdapat 40 data yang digunakan dalam uji coba, dari 40 hasil data tersebut disusun pada tabel yang terdiri dari nama pembeli, besar kuota, masa aktif, dan harga.

Tabel 1. Data uji coba pembelian paket data

\begin{tabular}{|c|c|c|c|c|c|c|c|c|c|}
\hline No & $\begin{array}{c}\text { Nama } \\
\text { Pembeli }\end{array}$ & $\begin{array}{l}\text { Besar } \\
\text { Kuota }\end{array}$ & $\begin{array}{l}\text { Masa } \\
\text { Aktif }\end{array}$ & Harga & No & $\begin{array}{c}\text { Nama } \\
\text { Pembeli }\end{array}$ & $\begin{array}{l}\text { Besar } \\
\text { Kuota }\end{array}$ & $\begin{array}{l}\text { Masa } \\
\text { Aktif }\end{array}$ & Harga \\
\hline 1 & Irene & 2,75 & 7 & 10 & 21 & Carol & 6 & 7 & 35 \\
\hline 2 & Liam & 10 & 30 & 50 & 22 & Anna & 25 & 30 & 100 \\
\hline 3 & Austin & 10 & 30 & 50 & 23 & Blake & 2 & 30 & 15 \\
\hline 4 & Tracey & 2,75 & 7 & 10 & 24 & Christopher & 2,75 & 7 & 10 \\
\hline 5 & Mary & 70 & 30 & 239 & 25 & Brian & 10 & 30 & 59 \\
\hline 6 & Tracey & 25 & 30 & 100 & 26 & Rose & 8 & 30 & 76 \\
\hline 7 & Nicholas & 10 & 30 & 59 & 27 & Felicity & 6 & 7 & 35 \\
\hline 8 & Christopher & 70 & 30 & 239 & 28 & Justin & 3 & 7 & 14 \\
\hline 9 & Deirdre & 3 & 7 & 14 & 29 & Richard & 2 & 30 & 39 \\
\hline 10 & Austin & 25 & 30 & 100 & 30 & Luke & 10 & 30 & 59 \\
\hline 11 & Victor & 10 & 30 & 50 & 31 & Theresa & 10 & 30 & 59 \\
\hline 12 & Samantha & 2 & 30 & 39 & 32 & Ava & 30 & 30 & 129 \\
\hline 13 & Ryan & 8 & 30 & 76 & 33 & Harry & 8 & 30 & 76 \\
\hline 14 & James & 10 & 30 & 50 & 34 & Amanda & 10 & 30 & 50 \\
\hline 15 & Brian & 6 & 7 & 35 & 35 & Evan & 10 & 30 & 50 \\
\hline 16 & Thomas & 10 & 30 & 50 & 36 & Stewart & 2,75 & 7 & 10 \\
\hline 17 & Dan & 2 & 30 & 39 & 37 & Hannah & 10 & 30 & 59 \\
\hline 18 & Joseph & 3 & 30 & 41 & 38 & Victor & 8 & 30 & 76 \\
\hline 19 & Ryan & 2 & 30 & 15 & 39 & Nicola & 18 & 30 & 75 \\
\hline
\end{tabular}




\begin{tabular}{llllllllll}
\hline 20 & Mary & 6 & 7 & 35 & 40 & Olivia & 6 & 7 & 35 \\
\hline
\end{tabular}

Dari 40 data tersebut kemudian ditentukan 3 cluster yang digunakan sebagai acuan dalam iterasi awal pada metode k-means yang digunakan. Cluster ini mewakili besaran paket yang umum tersedia, yaitu paket banyak, sedang dan sedikit. 3 cluster tersebut seperti ditunjukkan pada Tabel 2. Berdasarkan proses clustering yang dilakukan pada iterasi 1, maka diperoleh data iterasi 1 yang ditunjukkan dengan grafik iterasi 1 seperti pada Gambar 1 dan Gambar 2.
Tabel 2. Penentuan Cluster untuk Iterasi 1

\begin{tabular}{cccccc}
\hline No & Cluster & $\begin{array}{c}\text { Besar } \\
\text { Kuota }\end{array}$ & $\begin{array}{c}\text { Masa } \\
\text { Aktif }\end{array}$ & Harga & Jenis \\
\hline 1 & $\mathrm{C} 1$ & 2,75 & 7 & 10 & Sedikit \\
\hline 2 & $\mathrm{C} 2$ & 10 & 30 & 50 & Banyak \\
\hline 3 & $\mathrm{C} 3$ & 6 & 7 & 35 & Sedang \\
\hline
\end{tabular}

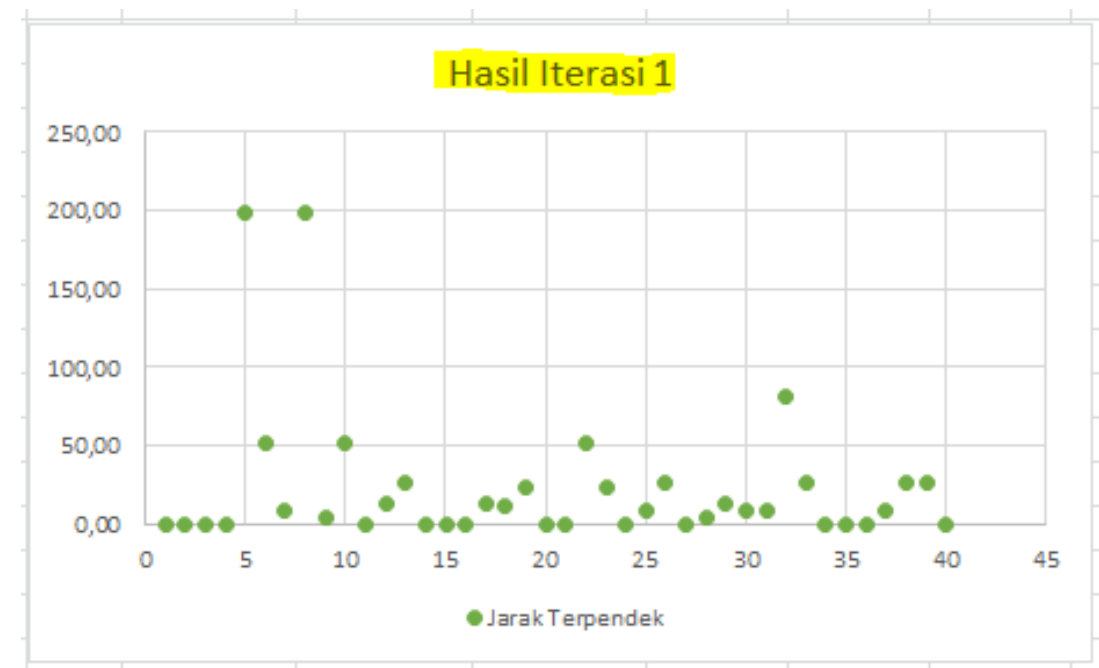

Gambar 1. Grafik data hasil iterasi 1

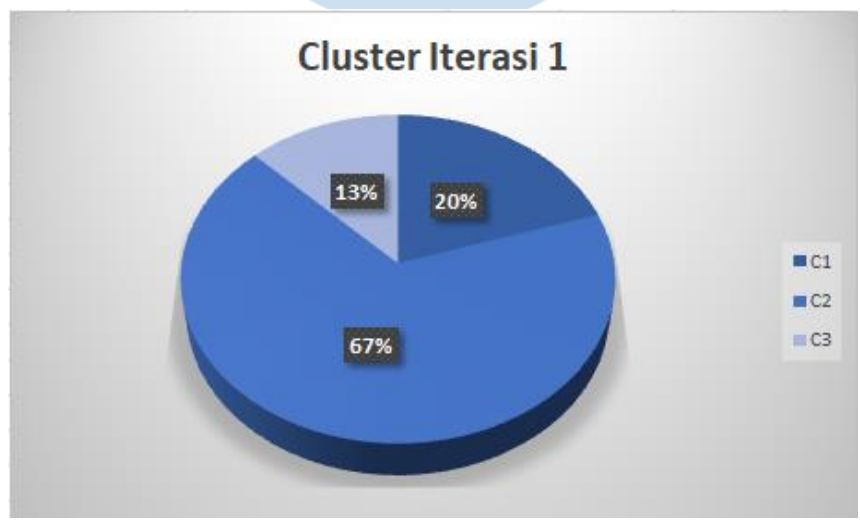

Gambar 2. Hasil Cluster Iterasi 1

Algoritme pengelompokan K-means dapat ditingkatkan secara signifikan dengan menggunakan teknik inisialisasi yang lebih baik, dan dengan mengulang (memulai kembali) algoritme tersebut [10].

Jika data memiliki cluster yang tumpang tindih, kmeans dapat meningkatkan hasil teknik inisialisasi. Ketika data memiliki cluster yang terpisah dengan baik, kinerja k-means sepenuhnya bergantung pada kebaikan inisialisasi.

Iterasi pada metode K-Means akan selalu dilakukan, sampai mendapatkan hasil yang optimal.
Pada proses metode K-Means pada literasi ke 2, diperoleh hasil yang belum optimal sehingga perlu dilakukan proses clustering perhitungan iterasi ke 3, dari hasil iterasi ke 3 diperoleh hasil yang optimal dari data uji coba yang digunakan. Dari hasil iterasi ke 3 ini akan dijadikan rujukan dalam penentuan hasil cluster yang dibentuk. Hasil penghitungan keseluruhan dari iterasi ke 3 ditunjukkan pada Tabel 3. Sedangkan grafik hasil iterasi ke 3 dan hasil cluster yang terbentuk seperti ditunjukkan pada Gambar 3 dan Gambar 4. 
Tabel 3. Hasil penghitungan iterasi ke 3

\begin{tabular}{|c|c|c|c|c|c|c|c|c|}
\hline No & $\begin{array}{c}\text { Nama } \\
\text { Pembeli }\end{array}$ & $\begin{array}{l}\text { Besar } \\
\text { Kuota } \\
\end{array}$ & $\begin{array}{l}\text { Masa } \\
\text { Aktif } \\
\end{array}$ & Harga & C1 & $\mathrm{C} 2$ & $\mathrm{C3}$ & $\begin{array}{c}\text { Jarak } \\
\text { Terpendek } \\
\end{array}$ \\
\hline 1 & Irene & 2,75 & 7 & 10 & 6,18 & 72,36 & 25,21 & 6,18 \\
\hline 2 & Liam & 10 & 30 & 50 & 42,15 & 27,96 & 27,75 & 27,75 \\
\hline 3 & Austin & 10 & 30 & 50 & 42,15 & 27,96 & 27,75 & 27,75 \\
\hline 4 & Tracey & 2,75 & 7 & 10 & 6,18 & 72,36 & 25,21 & 6,18 \\
\hline 5 & Mary & 70 & 30 & 239 & 237,17 & 170,51 & 215,04 & 170,51 \\
\hline 6 & Tracey & 25 & 30 & 100 & 92,18 & 24,47 & 71,52 & 24,47 \\
\hline 7 & Nicholas & 10 & 30 & 59 & 50,37 & 19,23 & 33,48 & 19,23 \\
\hline 8 & Christopher & 70 & 30 & 239 & 237,17 & 170,51 & 215,04 & 170,51 \\
\hline 9 & Deirdre & 3 & 7 & 14 & 6,02 & 68,60 & 21,21 & 6,02 \\
\hline 10 & Austin & 25 & 30 & 100 & 92,18 & 24,47 & 71,52 & 24,47 \\
\hline 11 & Victor & 10 & 30 & 50 & 42,15 & 27,96 & 27,75 & 27,75 \\
\hline 12 & Samantha & 2 & 30 & 39 & 31,84 & 40,74 & 23,69 & 23,69 \\
\hline 13 & Ryan & 8 & 30 & 76 & 66,26 & 7,82 & 47,05 & 7,82 \\
\hline 14 & James & 10 & 30 & 50 & 42,15 & 27,96 & 27,75 & 27,75 \\
\hline 15 & Brian & 6 & 7 & 35 & 23,71 & 49,18 & 0,00 & 0,00 \\
\hline 16 & Thomas & 10 & 30 & 50 & 42,15 & 27,96 & 27,75 & 27,75 \\
\hline 17 & Dan & 2 & 30 & 39 & 31,84 & 40,74 & 23,69 & 23,69 \\
\hline 18 & Joseph & 3 & 30 & 41 & 33,53 & 38,52 & 23,96 & 23,96 \\
\hline 19 & Ryan & 2 & 30 & 15 & 17,48 & 63,86 & 30,74 & 17,48 \\
\hline 20 & Mary & 6 & 7 & 35 & 23,71 & 49,18 & 0,00 & 0,00 \\
\hline 21 & Carol & 6 & 7 & 35 & 23,71 & 49,18 & 0,00 & 0,00 \\
\hline 22 & Anna & 25 & 30 & 100 & 92,18 & 24,47 & 71,52 & 24,47 \\
\hline 23 & Blake & 2 & 30 & 15 & 17,48 & 63,86 & 30,74 & 17,48 \\
\hline 24 & Christopher & 2,75 & 7 & 10 & 6,18 & 72,36 & 25,21 & 6,18 \\
\hline 25 & Brian & 10 & 30 & 59 & 50,37 & 19,23 & 33,48 & 19,23 \\
\hline 26 & Rose & 8 & 30 & 76 & 66,26 & 7,82 & 47,05 & 7,82 \\
\hline 27 & Felicity & 6 & 7 & 35 & 23,71 & 49,18 & 0,00 & 0,00 \\
\hline 28 & Justin & 3 & 7 & 14 & 6,02 & 68,60 & 21,21 & 6,02 \\
\hline 29 & Richard & 2 & 30 & 39 & 31,84 & 40,74 & 23,69 & 23,69 \\
\hline 30 & Luke & 10 & 30 & 59 & 50,37 & 19,23 & 33,48 & 19,23 \\
\hline 31 & Theresa & 10 & 30 & 59 & 50,37 & 19,23 & 33,48 & 19,23 \\
\hline 32 & Ava & 30 & 30 & 129 & 121,15 & 53,57 & 99,70 & 53,57 \\
\hline 33 & Harry & 8 & 30 & 76 & 66,26 & 7,82 & 47,05 & 7,82 \\
\hline 34 & Amanda & 10 & 30 & 50 & 42,15 & 27,96 & 27,75 & 27,75 \\
\hline 35 & Evan & 10 & 30 & 50 & 42,15 & 27,96 & 27,75 & 27,75 \\
\hline 36 & Stewart & 2,75 & 7 & 10 & 6,18 & 72,36 & 25,21 & 6,18 \\
\hline 37 & Hannah & 10 & 30 & 59 & 50,37 & 19,23 & 33,48 & 19,23 \\
\hline 38 & Victor & 8 & 30 & 76 & 66,26 & 7,82 & 47,05 & 7,82 \\
\hline 39 & Nicola & 18 & 30 & 75 & 66,87 & 3,30 & 47,68 & 3,30 \\
\hline 40 & Olivia & 6 & 7 & 35 & 23,71 & 49,18 & 0,00 & 0,00 \\
\hline
\end{tabular}




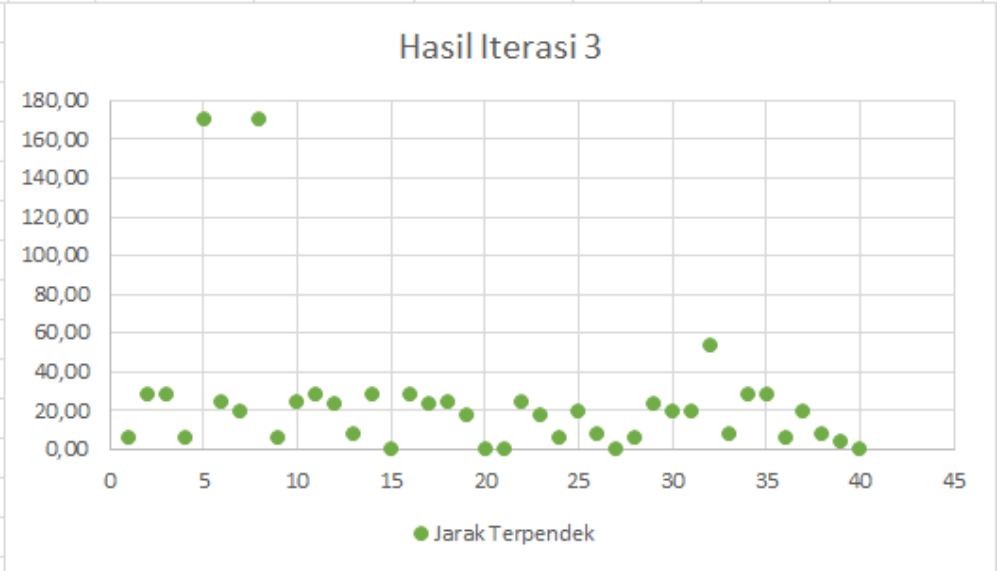

Gambar 3. Grafik data hasil iterasi 3

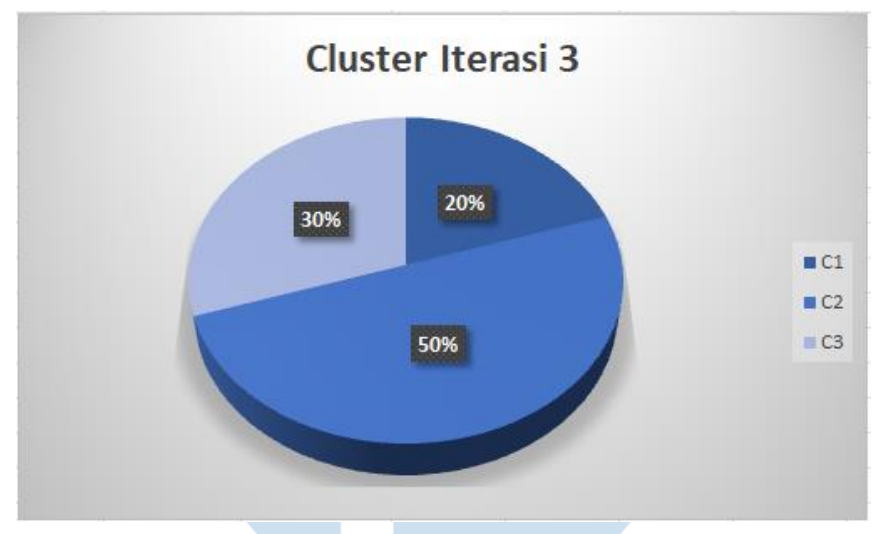

Gambar 4. Hasil Cluster Iterasi 3

Gambar 4 menunjukkan hasil cluster paling optimal yang terbentuk. Dari hasil perhitungan iterasi 3 yang merupakan hasil final dari rangkaian proses $\mathrm{K}$ Means yang sudah dijalankan sebelumnya, dari 40 data yang digunakan diperoleh suatu hasil akhir yang menunjukkan bahwa hasil yang terendah yaitu $\mathrm{C} 1$ (Cluster 1) dengan kelompok paket data dengan kuota sedikit, lama masa aktif sedang, dan harga paket data terjangkau, hasil sedang yaitu C3 (Cluster 3) dengan kelompok paket data dengan kuota sedang, lama masa aktif sedang, dan harga paket data terjangkau, dan hasil yang tertinggi yaitu C2 (Cluster 2) dengan kelompok paket data dengan kuota banyak, lama masa aktif sedang, dan harga paket data normal. Berdasarkan hasil uji coba yang diperoleh tersebut menunjukkan bahwa mayoritas penjualan berupa jumlah kuota banyak, masa aktif sedang dan harga normal.

\section{SIMPULAN}

Pengelompokan paket penjualan paket data dengan 40 data yang telah diuji dapat dianalisis dengan menggunakan metode K-Means Clustering. Berdasarkan uji coba yang telah dilakukan diperoleh hasil optimal pada iterasi ke 3 dengan hasil akhir yang menunjukkan bahwa hasil yang terendah yaitu $\mathrm{C} 1$ (Cluster 1), hasil sedang yaitu C3 (Cluster 3), dan hasil yang tertinggi yaitu C2 (Cluster 2). Dari hasil tersebut menunjukkan jika penjualan terbanyak berupa kuota banyak menjadi pilihan favorit.

\section{DAFTAR PUSTAKA}

F. Liantoni and L. Cahyani, "Pemanfaatan Hierarchical Clustering Untuk Pengelompokkan Daun Berdasarkan Fitur Moment Invariant," J. Ilm. Edutic, Univ. Trunojoyo Madura, vol. 3, no. 2, pp. 91-98, 2017.

[2] F. Liantoni, N. Ramadijanti, and N. Rosyid Mubtada'i, "Klasifikasi Daun Dengan Centroid Linked Clustering Berdasarkan Fitur Bentuk Tepi Daun," EEPIS Final Proj., 2010.

[3] B. Everitt, S. Landau, M. Leese, and D. Stahl, Cluster Analysis. West Sussex, U.K: Wiley: Chichester, 2011.

[4] A. Al-Wakeel and J. Wu, "K-means Based Cluster Analysis of Residential Smart Meter Measurements," Energy Procedia, vol. 88, pp. 754-760, Jun. 2016, doi: 10.1016/j.egypro.2016.06.066.

[5] X. Wu et al., "Top 10 algorithms in data mining," Knowl. Inf. Syst., vol. 14, no. 1, pp. 1-37, Jan. 2008, doi: 10.1007/s10115-007-0114-2.

[6] Y. Li and H. Wu, "A Clustering Method Based on KMeans Algorithm," Phys. Procedia, vol. 25, pp. 11041109, 2012, doi: 10.1016/j.phpro.2012.03.206.

[7] Agusta, "K-means Penerapan, Permasalahan dan Metode Terkait," J. Sist. dan Inform., vol. 3, 2007.

[8] L. Rokach and O. Maimon, "Clustering Methods," in Data Mining and Knowledge Discovery Handbook, Springer, Boston, MA, 2005, pp. 321-352.

[9] K. Tian, J. Li, J. Zeng, A. Evans, and L. Zhang, "Segmentation of tomato leaf images based on adaptive clustering number of K-means algorithm," Comput. 
Electron. Agric., vol. 165, p. 104962, Oct. 2019, doi: 10.1016/j.compag.2019.104962.

[10] P. Fränti and S. Sieranoja, "How much can k-means be improved by using better initialization and repeats?,' Pattern Recognit., vol. 93, pp. 95-112, Sep. 2019, doi: 10.1016/j.patcog.2019.04.014. 